\title{
Intravitreal bevacizumab injections for diabetic macular edema - predictors of response: a retrospective study
}

This article was published in the following Dove Press journal:

Clinical Ophthalmology

21 October 2016

Number of times this article has been viewed

Lavnish Joshi ${ }^{1-3}$

Asaf Bar ${ }^{4}$

Oren Tomkins-Netzer ${ }^{1,3}$

Satish Yaganti ${ }^{\prime}$

Jiten Morarji'

Panayiotis Vouzounis'

Sophie Seguin-Greenstein ${ }^{1,4}$

Simon R Taylor ${ }^{3,5}$

Sue Lightman ${ }^{1,3}$

'Department of Clinical

Ophthalmology, UCL Institute of Ophthalmology and Moorfields Eye

Hospital, London, UK; ${ }^{2}$ Ophthalmology

Department, Ashford \& St Peter's

NHS Foundation Trust, Ashford,

Middlesex, UK; ${ }^{3}$ Ophthalmology

Department, Royal Surrey County

Hospital NHS Foundation Trust,

Guildford, Surrey, UK; ${ }^{4}$ Ophthalmology

Department, Wolfson Medical

Center, Holon Israel; ${ }^{5}$ Ophthalmology

Department, University of Surrey,

Guildford, Surrey, UK
Correspondence: Sue Lightman

UCL Institute of Ophthalmology,

Moorfields Eye Hospital, 162 City Road,

London ECIV 2PD, UK

Tel +442075662266

Email s.lightman@ucl.ac.uk
Background: Outcomes of intravitreal antivascular endothelial growth factor injections are variable among patients with diabetic macular edema (DME). The aim of this study was to determine the ocular and systemic predictors of DME response to intravitreal bevacizumab (IVB).

Methods: Retrospective review over 2 years of 78 eyes from 54 patients. An anatomical response to IVB was defined as a $20 \%$ reduction in central macula thickness after the first course (three injections) of IVB.

Results: Twenty-eight percent of patients had an anatomical response after the first course of IVB. Systemic hypertension (odds ratio, 95\% confidence interval: 12.1, 0.7-21) was a statistically significant predictor $(P=0.025)$ of a good response to IVB, whereas previous macular laser was a statistically significant $(P=0.0005)$ predictor of a poor response $(0.07,0.01-0.32)$. Sixty-eight percent of eyes underwent subsequent treatment for DME after the first course of IVB. The visual acuity gain at 24 months in hypertensive $(0.7 \pm 3.6$ letters $)$ and nonhypertensive (5.2 \pm 3.7 letters) patients was not significantly different $(P=0.41)$.

Conclusion: Hypertension and previous macular laser were positive and negative predictors of response to IVB, respectively. However, long-term visual acuity changes were not significantly different between eyes with and without systemic hypertension.

Keywords: diabetes, macular edema, intravitreal therapy

\section{Background}

Diabetic macular edema (DME) is one of the leading causes of visual impairment. ${ }^{1}$ Traditionally, macular laser photocoagulation has been the gold standard treatment for managing DME based on results from the Early Treatment Diabetic Retinopathy Study (ETDRS). ${ }^{2}$ However, intravitreal injections of vascular endothelial growth factor (VEGF) inhibitors have demonstrated better outcomes when compared to laser photocoagulation, with good quality evidence from several randomized controlled trials. ${ }^{3-5}$

Bevacizumab is an anti-VEGF antibody available as an off-label therapy in the UK for DME; it is considerably cheaper than the licensed drug ranibizumab and has similar gains in visual acuity (VA) compared to other intravitreal anti-VEGF agents for most subgroup of patients. ${ }^{5,6}$ Long-term results with intravitreal bevacizumab (IVB) at 24 months have demonstrated statistically significant gains in VA compared to laser, with patients receiving a median number of 13 treatments during this time. ${ }^{7}$ Outcomes seem to be variable among patients, so recent reports have focused on identifying predictors of response. These have looked at systemic ${ }^{8,9}$ or ocular factors, ${ }^{10}$ but not in conjunction with each other, which could be important since these factors may be interrelated. 
The aim of this study is to address these issues and determine the ocular and systemic predictors of DME response to IVB in a large cohort of patients.

\section{Methods}

We conducted a retrospective consecutive case series review of 53 patients (74 eyes) who received one or more courses of IVB injections (Avastin, Roche Registration Limited, Welwyn Garden City, UK) for the treatment of DME at the Royal Surrey County Hospital (Guildford, UK) during the period May 1, 2011 to December 31, 2013, who had at least 1 year of follow-up. Each IVB injection $(1.25 \mathrm{mg} / 0.05 \mathrm{~mL})$ was prepared by the hospital pharmacy as a prefilled syringe containing $0.10 \mathrm{~mL}$, with only $0.05 \mathrm{~mL}$ being injected into an eye. This study was approved by the Royal Surrey County Hospital Research Ethics Committee (outcomes of retinal disease: RSCH/12DEV0010). Due to the observational and retrospective nature of the study, for which data were obtained from review of medical charts, with no intervention or deliberate modification of treatment, patient informed consent was waived by the committee.

Patients who had recurrent/persistent DME after laser photocoagulation for DME or patients who had DME close to the fovea were included in the study. Patients were excluded if they had $<12$ months of follow-up from their first injection. There were no patients who had previously received other intravitreal therapies or had other ophthalmic diagnoses related to macular edema.

The injections were performed under sterile conditions, with topical anesthesia using a standardized technique, including the use of topical povidone-iodine $5 \%$ and a lid speculum. ${ }^{11}$ The injections were placed with a 30 -gauge needle through the supra- or infratemporal quadrant. Topical ciprofloxacin was given four times a day for 5 days postoperatively.

Baseline ocular and systemic comorbidities were recorded, as were previous treatments with laser photocoagulation. Baseline and follow-up visits included ETDRS VA charts, clinical examination, intraocular pressure (IOP) measurement, optical coherence tomography (OCT) scanning using a TopCon 3D OCT-1000 scanner (Topcon Corp., Tokyo, Japan). Fundus fluorescein angiography using a digital retinal camera system (Topcon TRC 50IX, Topcon Medical Systems Inc., Paramus, NJ, USA) was performed at the baseline visit.

A course of injections included three injections given 4 weeks apart and was followed by a doctor's review with an OCT scan 4 weeks after the third injection. A repeat course of injections was given if the patient had any clinical/OCT evidence of DME. During the study period, four eyes received panretinal laser photocoagulation and one eye underwent cataract surgery. The study period ended at the last follow-up or at the time of eyes subsequently receiving other intravitreal therapies or macula laser for DME, whichever was sooner.

We classified anatomical responders as those with evidence of a central macula thickness (CMT) reduction of $\geq 20 \%$ after the first course of three injections, in line with previous studies of anti-VEGF intravitreal therapy.,12

\section{OCT analysis}

OCT scans from every visit were reviewed to determine the CMT. OCT scans at baseline and at 12 months were also reviewed to determine the status of the inner segmentouter segment junction. This was taken as the first hyperreflective line above the retinal pigment epithelium on the OCT scan, and is believed to represent the integrity of the photoreceptor layer. ${ }^{13,14}$ A three-step scale was used to evaluate the line: normal, abnormal (speckled or irregular line), and absent.

\section{Fluorescein angiography}

Foveal avascular zone outline was classified according to the ETDRS grading system: from 0 (normal), to 1 (questionable), 2 (less than half the original circumference destroyed), 3 (more than half the contour destroyed but some remnants remain), and 4 (capillary outline completely destroyed). ${ }^{15}$

\section{Statistical analysis}

All data was entered into a Microsoft Excel 2010 spreadsheet (Microsoft Corporation, Redmond, WA, USA). Analyses and graphs were constructed using GraphPad Prism v5.01 (La Jolla, CA, USA), and PASW Statistics 18 (v18.0.0; SPSS Inc., Chicago, IL, USA). A $P$-value $\leq 0.05$ was accepted as statistically significant. Changes in variables were compared by Wilcoxon and Mann-Whitney test; proportions between groups were compared using the $\chi^{2}$ test, Fisher's test, or McNemar test. Logistic regression was used to evaluate potential predictors of response, generating odds ratios.

\section{Results}

A total of 74 eyes from 53 patients were included in the study. The median total follow-up time after the first injection of IVB was 23.5 months (range, 12-34 months). The total number of IVB injections during the study period was 345 . Baseline patient characteristics are summarized in Table 1. Sixty-one percent of eyes received previous macular laser for DME, with a median of one laser session (range, 1-7).

\section{Response to first course}

Figure 1 illustrates the distribution of the \% change in CMT after the first course of IVB. Twenty-three percent of eyes had 
Table I Baseline characteristics of patients

\begin{tabular}{|c|c|}
\hline Characteristics & All patients \\
\hline Age, years; median (range) & $65(23-86)$ \\
\hline \multicolumn{2}{|l|}{ Sex $(\%)$} \\
\hline Female & 31 \\
\hline Male & 69 \\
\hline \multicolumn{2}{|l|}{ Type of DM (\%) } \\
\hline Type I & 12 \\
\hline Type 2 & 88 \\
\hline \multicolumn{2}{|l|}{ DM treatment (\%) } \\
\hline Insulin & 24 \\
\hline Tablets & 14 \\
\hline Both & 62 \\
\hline Duration of DM, years; median (range) & $13(2-60)$ \\
\hline Nephropathy (\%) & 13 \\
\hline Mean HbAlc (SD) & $7.74(2.13)$ \\
\hline Mean systolic BP (SD) & $150(2 \mid)$ \\
\hline Median baseline visual acuity, ETDRS letters (range) & $70(0-85)$ \\
\hline Mean baseline central macular thickness, $\mu \mathrm{m}$ (SD) & $394(121)$ \\
\hline Duration of DME, months; (median, range) & $14(0-1 \mid 8)$ \\
\hline Previous macular laser (\%) & 61 \\
\hline Previous PRP laser (\%) & 23 \\
\hline \multicolumn{2}{|l|}{ Retinopathy grade (\%) } \\
\hline Mild/moderate & 64 \\
\hline Severe/PDR & 18 \\
\hline Treated PDR & 18 \\
\hline \multicolumn{2}{|l|}{ Lens status (\%) } \\
\hline Phakic & 77 \\
\hline Pseudophakic & 23 \\
\hline \multicolumn{2}{|l|}{ OCT morphology (\%) } \\
\hline Cystoid & 81 \\
\hline Diffuse retinal thickening & 13 \\
\hline Serous detachment & 6 \\
\hline
\end{tabular}

Abbreviations: BP, blood pressure; DM, diabetes mellitus; DME, diabetic macular edema; ETDRS, Early Treatment Diabetic Retinopathy Study; OCT, optical coherence tomography; PDR, proliferative diabetic retinopathy; PRP, panretinal photocoagulation; SD, standard deviation.

a reduction in $\mathrm{CMT}$ of $>20 \%$. In line with the previous studies, these patients were regarded as anatomical responders. After the first course, a gain of $\geq 5$ letters was seen in $43 \%$ of anatomical responders and $32 \%$ of nonresponders.

The mean baseline CMT was significantly higher $(P=0.0350)$ for responders $(456 \pm 4.1 \mu \mathrm{m}$, mean \pm standard

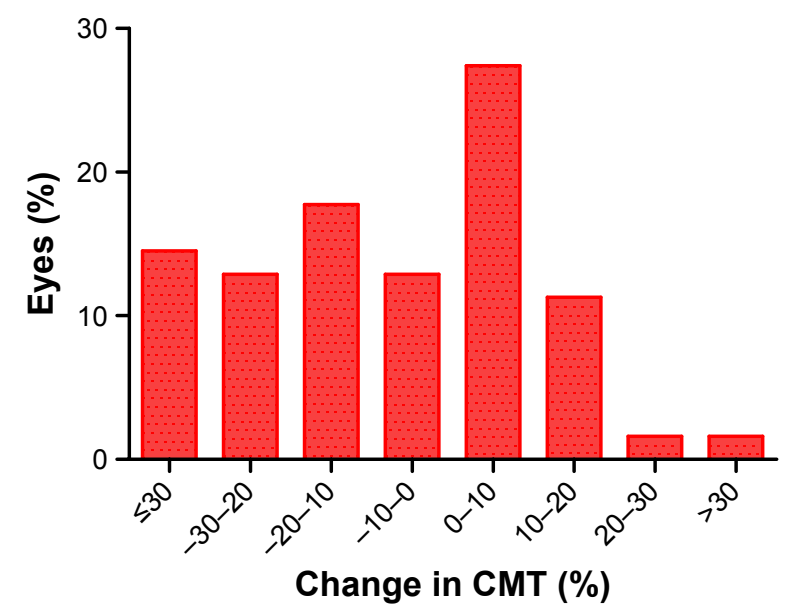

Figure I Distribution of the change in CMT after the first course of intravitreal bevacizumab injections.

Abbreviation: CMT, central macular thickness. error of the mean) than nonresponders $(380 \pm 17.2 \mu \mathrm{m})$. The mean baseline VA was not significantly different $(P=0.976)$ for responders $(62.4 \pm 4.5$ letters $)$ and nonresponders (62.3 \pm 2.5 letters).

\section{Predictors of response}

Table 2 shows a univariate analysis of potential predictors of response to the first course of IVB. A multivariate logistic regression analysis was not possible due to the number of subjects. Systemic hypertension was a statistically significant ( $P=0.025$ ) predictor of response to IVB, increasing the odds of response to over 12 times compared to not being hypertensive. The mean baseline CMT was not significantly different $(P=0.0597)$ between hypertensive patients $(413 \pm 18.5 \mu \mathrm{m})$ and nonhypertensive patients $(366 \pm 30.5 \mu \mathrm{m})$.

Previous macula laser was a statistically significant $(P=0.0005)$ predictor of poor response (odds ratio $=0.07$ ). The mean baseline CMT was not significantly different $(P=0.59)$ between patients who had previous laser $(414 \pm 39.4 \mu \mathrm{m})$ and no previous laser $(394 \pm 16.9 \mu \mathrm{m})$.

\section{Long-term outcomes}

Sixty-eight percent of eyes underwent subsequent treatment for DME after the first course of IVB. Long-term VA changes in eyes that did and did not achieve an anatomical response after the first course of IVB are demonstrated in Figure 2. Although, at 12 months, the mean VA gain was lower in the responder group ( $0.4 \pm 5.4$ letters) vs nonresponders $(3.4 \pm 1.8$ letters), this was not statistically significant $(P=0.86)$. This finding along with the wide error bars in the responder group

Table 2 Predictors of response after first course of intravitreal bevacizumab injections in DME patients

\begin{tabular}{|c|c|c|}
\hline \multirow[t]{2}{*}{ Factor } & \multicolumn{2}{|l|}{ Unadjusted } \\
\hline & $\begin{array}{l}\text { Odds ratio } \\
(95 \% \mathrm{Cl}) \\
\end{array}$ & $P$-value \\
\hline Duration of DME $>12$ months & $0.57(1.7-1.9)$ & 0.54 \\
\hline Baseline $\mathrm{HbAlc}>7.4 \%$ & $1.9(0.47-7.6)$ & 0.48 \\
\hline Diabetic treatment insulin vs no insulin & $1.7(0.6-5.3)$ & 0.40 \\
\hline Hypertension & $12.1(0.7-219)$ & $0.025^{*}$ \\
\hline Smoking & $0.61(0.1-3.3)$ & 0.71 \\
\hline Ischemic heart disease & $4.8(0.7-31.9)$ & 0.12 \\
\hline Nephropathy & $2.25(0.45-11.3)$ & 0.38 \\
\hline DR grade PDR (prior PRP) & $3.5(1 . I-1 \mid .2)$ & 0.065 \\
\hline Previous macula laser & $0.07(0.01-0.32)$ & $0.0005^{*}$ \\
\hline Foveal avascular zone grade $>2$ & $1.7(0.3-9.5)$ & 0.70 \\
\hline $\begin{array}{l}\text { OCT IS-OS junction present } \\
\text { vs absent/ abnormal }\end{array}$ & $0.85(0.28-2.6)$ & 0.78 \\
\hline $\begin{array}{l}\text { OCT morphology subretinal fluid vs no } \\
\text { subretinal fluid }\end{array}$ & $3.1(0.4-23.9)$ & 0.30 \\
\hline
\end{tabular}

Note: $* p<0.05$.

Abbreviations: $\mathrm{Cl}$, confidence interval; $\mathrm{DME}$, diabetic macular edema; $\mathrm{DR}$, diabetic retinopathy; IS-OS, inner segment outer segment; OCT, optical coherence tomography; PDR, proliferative diabetic retinopathy; PRP, panretinal photocoagulation. 


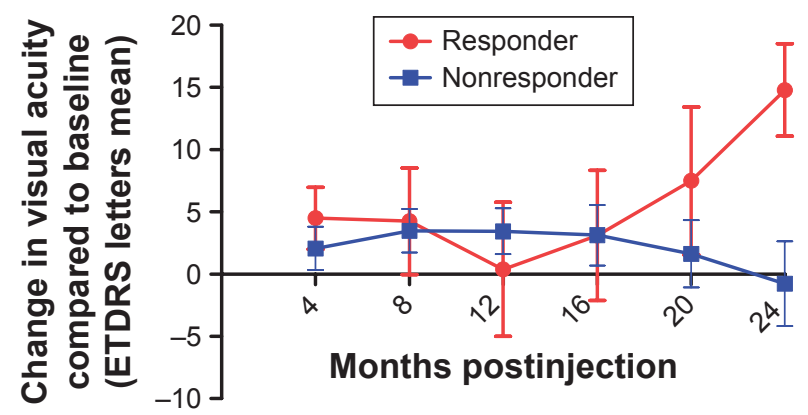

Figure 2 Long-term changes in visual acuity after the first intravitreal bevacizumab injection in diabetic macular edema responders and nonresponders.

Abbreviation: ETDRS, Early Treatment Diabetic Retinopathy Study.

suggests that changes in CMT and best corrected VA do not always correlate with each other initially. However, at 24 months, there was a significant difference $(P<0.0001)$ in VA gain in the responders ( $14.8 \pm 3.7$ letters) vs nonresponders $(-0.8 \pm 3.4$ letters $)$.

The VA gain at 24 months in hypertensive $(0.7 \pm 3.6$ letters) and nonhypertensive (5.2 \pm 3.7 letters) patients was also not significantly different $(P=0.41)$.

\section{Discussion}

This study demonstrates that, in a large cohort of DME patients, only $23 \%$ of eyes showed a response via a reduction in CMT ( $>20 \%)$ after the first course of IVB, with hypertension and previous macular laser being statistically significant positive and negative predictors of response, respectively. Long-term VA changes with subsequent IVB courses were similar in responders and nonresponders, but responders had a significantly greater gain in VA at 24 months.

In the bevacizumab or laser therapy in DME treatment (BOLT) study, almost $38 \%$ of eyes receiving IVB (total 34 eyes that completed 24 months follow-up) had a response (CMT reduction $>20 \%$ ) after the first course. ${ }^{9}$ In our study, only $23 \%$ of eyes achieved this. The lower mean baseline CMT in our cohort could have been attributed to a "ceiling" effect whereby the relative CMT change would have been less. Indeed, in our cohort, the mean baseline CMT was significantly higher in responders (CMT improvement $>20 \%$ ) than nonresponders.

We chose to analyze the response of DME after the first course of IVB since the BOLT study had shown that the majority of eyes demonstrated a response after the first course. ${ }^{16}$ Additionally, an end-point analysis at 12 months may lead to the outcomes being dependent on the variability in the number of injections received. The BOLT study demonstrated that $21 \%$ of IVB eyes that did not respond to the first course, responded to subsequent courses, with these eyes also demonstrating a gain in VA $(50 \%$ of eyes gained $>15$ letters). ${ }^{16}$ In our study, "nonresponders" (CMT reduction $<20 \%$ after the first course of IVB) demonstrated similar gains in VA compared to "responders", also highlighting that persisting edema after the first course of IVB should not be used as a criterion for stopping treatment.

Certain OCT morphological features (subretinal fluid and integrity of photoreceptor inner and outer segment line beneath the fovea) have been shown to be predictive of OCT responsiveness for DME treated with intravitreal anti-VEGF therapy in small case series. ${ }^{17}$ However, our findings are consistent with a recent large post hoc analysis of data from several randomized controlled trials, which found that in DME patients receiving monthly injections of ranibizumab, OCT morphology was not predictive of poor OCT response. In sham-injected eyes, OCT morphology was a predictor of poor response, suggesting that anti-VEGF agents can overcome such features. ${ }^{18}$

Hypertension is a risk factor for developing diabetic retinopathy. ${ }^{19}$ In our study, hypertension (a diagnosis made at baseline) was a statistically significant positive predictor of response after the first course of IVB. The effects of antihypertensive medications may have made this group of patients more responsive to the effects of IVB; however, hypertension has not been found to be a predictive factor for VA outcomes in DME patients receiving macular laser. ${ }^{20}$ The effects of different antihypertensive agents in the progression of diabetic retinopathy do not appear to be class-specific; ${ }^{21}$ however, future studies on large cohorts should determine if they play a role influencing macular thickness and VA outcomes after IVB therapy for DME, since there is some evidence to suggest that treatment with systemic beta-adrenergic blocking agents may reduce the need for repeated IVB injections in wet age-related macular degeneration. ${ }^{22}$ It is also possible that some patients in our cohort not on antihypertensive medication at baseline could have represented untreated hypertensive patients, which may have limited the responsiveness to IVB due to continued hypertension. Indeed, up to $30 \%$ of diabetics can have undiagnosed/untreated hypertension. ${ }^{23,24}$ However, treating hypertension has not been found to reduce the progression to clinically significant DME in patients with established retinopathy. ${ }^{21}$

A recent study found that blood pressure and nephropathy were not predictive of poor response (OCT and visual improvement) in DME patients treated with anti-VEGF agents, which is consistent with our findings. However, 
in sham-treated patients, these factors were predictive of response, suggesting that sustained inhibition of VEGF can overcome these poor prognostic features. ${ }^{18}$

A few studies have looked at the impact of other metabolic parameters in DME response to VEGF inhibition. One study looked at the response after a one-dose injection of ranibizumab and found that serum $\mathrm{HbA} 1 \mathrm{c}$ levels were negatively correlated with the change in $\mathrm{CMT}^{8}$ Another study examined the effects of IVB on CMT at 1 year and found that patients with $\mathrm{HbA} 1 \mathrm{c}$ levels $\leq 7.0 \%$ at baseline had greater reductions in CMT (statistically significant) than patients with a HbAlc level $\geq 7.0 \% .{ }^{25}$ We did not find such an effect in our patients, although such an effect may be biologically plausible. This difference in findings may be due to the way we defined responsiveness (CMT change $>20 \%$ ), which may be a more robust end point than just examining numerical values in the aforementioned studies.

Prior treatment with macula laser was a statistically significant predictor of unresponsiveness in our study, which does not seem consistent with previous studies. In the BOLT study, all patients had prior treatment with laser, but the number of laser treatments was not associated with the change in CMT at 24 months. ${ }^{9}$ Another study found no difference in CMT change after a single injection of IVR in patients who had previous treatment for DME versus those that did not; however, the former group did have a greater gain in VA. ${ }^{8}$ The patients in our cohort who had previous macular laser could represent a more treatment-refractory group.

\section{Conclusion}

This study demonstrates that systemic hypertension and previous macular laser were statistically significant positive and negative predictors of DME response to IVB, respectively. The limitations of our study include its retrospective nature and treatment bias. Further studies are needed to determine the influence on antihypertensive medications on the responsiveness of DME.

\section{Author contributions}

$\mathrm{AB}, \mathrm{LJ}, \mathrm{OT}-\mathrm{N}$, and SL were involved in the conception and design of the project. AB, LJ, PV, JM, SY, and SG-G were involved in the acquisition of data. LJ, OT-N, JM, and SL were involved with the analysis and interpretation of data. AB, LJ, OT-N, ST, and SL were involved in the conceptualization of the manuscript and review and synthesis of the literature. LJ and OT-N were involved with the drafting of the manuscript. All authors critically reviewed, revised, and approved the final manuscript.

\section{Disclosure}

ST reports grants, personal fees, and nonfinancial support from Novartis AG, personal fees and nonfinancial support from Allergan Plc, personal fees from Santen Inc., personal fees from Bayer AG outside the submitted work. LJ reports receiving grants from the National Institute for Health Research outside the submitted work. SL reports grants and personal fees from Allergan Plc, grants and personal fees from GSK, grants and personal fees from Bayer AG, personal fees from Santen Inc., outside the submitted work. The authors report no other conflicts of interest in this work.

\section{References}

1. Pascolini D, Mariotti SP. Global estimates of visual impairment: 2010 Br J Ophthalmol. 2012;96(5):614-618.

2. Photocoagulation for diabetic macular edema. Early treatment diabetic retinopathy study report number 1 . Early treatment diabetic retinopathy study research group. Arch Ophthalmol. 1985;103(12):1796-1806.

3. Michaelides M, Kaines A, Hamilton RD, et al. A prospective randomized trial of intravitreal bevacizumab or laser therapy in the management of diabetic macular edema (BOLT study) 12-month data: report 2. Ophthalmology. 2010;117(6):1078-1086.

4. Mitchell P, Bandello F, Schmidt-Erfurth U, et al. The RESTORE study: ranibizumab monotherapy or combined with laser versus laser monotherapy for diabetic macular edema. Ophthalmology. 2011; 118(4):615-625.

5. Diabetic Retinopathy Clinical Research Network; Wells JA, Glassman AR, Ayala AR, et al. Aflibercept, bevacizumab, or ranibizumab for diabetic macular edema. N Engl J Med. 2015;372(13):1193-1203.

6. Group CR, Martin DF, Maguire MG, et al. Ranibizumab and bevacizumab for neovascular age-related macular degeneration. $N$ Engl J Med. 2011;364(20):1897-1908.

7. Rajendram R, Fraser-Bell S, Kaines A, et al. A 2-year prospective randomized controlled trial of intravitreal bevacizumab or laser therapy (BOLT) in the management of diabetic macular edema: 24-month data: report 3. Arch Ophthalmol. 2012;130(8):972-979.

8. Ozturk BT, Kerimoglu H, Adam M, Gunduz K, Okudan S. Glucose regulation influences treatment outcome in ranibizumab treatment for diabetic macular edema. J Diabetes Complications. 2011;25(5): 298-302.

9. Sivaprasad S, Crosby-Nwaobi R, Esposti S, et al. Structural and functional measures of efficacy in response to bevacizumab monotherapy in diabetic macular oedema: exploratory analyses of the BOLT study (report 4). PLoS One. 2013;8(8):e72755.

10. Koytak A, Altinisik M, Sogutlu Sari E, Artunay O, Umurhan Akkan JC, Tuncer K. Effect of a single intravitreal bevacizumab injection on different optical coherence tomographic patterns of diabetic macular oedema. Eye (Lond). 2013;27(6):716-721.

11. Royal College of Ophthalmologists. Guidelines for Intravitreal Injections Procedure; 2009. Available from: http://www.rcophth.ac.uk/core/ core_picker/download.asp?id=167\&filetitle=Guidelines+for+Intravitr eal+Injections+Procedure+2009. Accessed March 3, 2015.

12. Bressler SB, Qin H, Beck RW, et al. Factors associated with changes in visual acuity and central subfield thickness at 1 year after treatment for diabetic macular edema with ranibizumab. Arch Ophthalmol. 2012; 130(9):1153-1161.

13. Wong IY, Iu LP, Koizumi H, Lai WW. The inner segment/outer segment junction: what have we learnt so far? Curr Opin Ophthalmol. 2012;23(3):210-218.

14. Domalpally A, Peng Q, Danis R, et al. Association of outer retinal layer morphology with visual acuity in patients with retinal vein occlusion: SCORE Study Report 13. Eye (Lond). 2012;26(7):919-924. 
15. Classification of diabetic retinopathy from fluorescein angiograms. ETDRS report number 11. Early Treatment Diabetic Retinopathy Study Research Group. Ophthalmology. 1991;98(5 Suppl):807-822.

16. Sivaprasad S, Crosby-Nwaobi R, Heng LZ, Peto T, Michaelides M, Hykin P. Injection frequency and response to bevacizumab monotherapy for diabetic macular oedema (BOLT Report 5). Br J Ophthalmol. 2013;97(9):1177-1180.

17. Roh MI, Kim JH, Kwon OW. Features of optical coherence tomography are predictive of visual outcomes after intravitreal bevacizumab injection for diabetic macular edema. Ophthalmologica. 2010;224(6): 374-380.

18. Sophie R, Lu N, Campochiaro PA. Predictors of functional and anatomic outcomes in patients with diabetic macular edema treated with ranibizumab. Ophthalmology. 2015;122(7):1395-1401.

19. UKPDS38. Tight blood pressure control and risk of macrovascular and microvascular complications in type 2 diabetes: UKPDS 38 . UK Prospective Diabetes Study Group. BMJ. 1998;317(7160):703-713.

20. Jyothi S, Sivaprasad S. Five-year visual outcome following laser photocoagulation of diabetic macular oedema. Eye (Lond). 2011;25(7): 851-858; quiz 859.
21. Do DV, Wang X, Vedula SS, et al. Blood pressure control for diabetic retinopathy. Cochrane Database Syst Rev. 2015;1:CD006127.

22. Montero JA, Ruiz-Moreno JM, Sanchis-Merino E, Perez-Martin S. Systemic beta-blockers may reduce the need for repeated intravitreal injections in patients with wet age-related macular degeneration treated by bevacizumab. Retina. 2013;33(3):508-512.

23. de Burgos-Lunar C, Jimenez-Garcia R, Salinero-Fort MA, et al. Trends in hypertension prevalence, awareness, treatment and control in an adult type 2 diabetes Spanish population between 2003 and 2009. PLoS One. 2014;9(1):e86713.

24. Geiss LS, Rolka DB, Engelgau MM. Elevated blood pressure among U.S. adults with diabetes, 1988-1994. Am J Prev Med. 2002;22(1):42-48.

25. Matsuda S, Tam T, Singh RP, et al. The impact of metabolic parameters on clinical response to VEGF inhibitors for diabetic macular edema. J Diabetes Complications. 2014;28(2):166-170.
Clinical Ophthalmology

\section{Publish your work in this journal}

Clinical Ophthalmology is an international, peer-reviewed journal covering all subspecialties within ophthalmology. Key topics include: Optometry; Visual science; Pharmacology and drug therapy in eye diseases; Basic Sciences; Primary and Secondary eye care; Patient Safety and Quality of Care Improvements. This journal is indexed on

\section{Dovepress}

PubMed Central and CAS, and is the official journal of The Society of Clinical Ophthalmology (SCO). The manuscript management system is completely online and includes a very quick and fair peer-review system, which is all easy to use. Visit http://www.dovepress.com/ testimonials.php to read real quotes from published authors. 